Monatsschrift f. Geburtshülfe u. Gynäkologie 1916;44:257

\title{
Lieber Carl Ruge!
}

Am heutigen Tage vollendest Du das siebenzigste Lebensjahr! Gleichzeitig damit rundet sich das neunte Lustrum Deiner Arbeit in der Frauenklinik! Nur diese Zeitläufte verschulden, daß nicht aus alien Richtungen der Windrose Deine Freunde, Mitarbeiter und Schüler herbei-kommen, um diesen Tag festlich mit Dir zu begehen. Er-blicke in uns, die wir Dir hier ein treugemeintes Ange-binde darbringen, die Vertreter aller der Generationen, welche in diesen nahezu zwei Menschenaltern mit Dir gelebt und gestrebt habem Vor 45 Jahren hat Eduard Martin Dich zur Mit-arbeit an die Frauenklinik berufen mit dem Auftrag, die klinische Arbeit durch eine rein wissenschaftliche zu stützen und zu befruchten. Mit vollster Sachverständigkeit und unermüdlicher Hingabe hast Du nun nahezu 5 Dezennien hindurch diesem Ziel in Treuen nachgestrebt, das Ideal eines wissenschaftlichen Generalstäblers! Du hast als Frucht Deiner selbstlosen Arbeit die Befriedigung, daß alle, welche an Deiner Seite gearbeitet haben, Dir eine Fülle von An-regung und Belehrung verdanken, deren Spuren neben Deinen eigenen grundlegenden Arbeiten in der Geschichte der Frauenheilkunde nicht nur dem Eingeweihten unver-kennbar hervortreten.

Laß' diese Festschrift Dir am heutigen Tage unser aller Dank bezeugen für Deine treue, selbstlose, werktätige Freundschaft! Mögen Dir noch Lustren beschieden sein, Dich an dem reichen Erfolg Deiner Lebensarbeit zu erfreuen!

Berlin, 24. September 1916.

A. Martin. Paul Ruge. J. Veit.

Max Hofmeier. Ernst Bumm. R. Meyer. K. Warnekros.

P. Schäfer. F. Fehim. Carl Ruge II. 